\title{
LA NOTA MARGINAL MARIA EX STIRPE DANIELIS EN LA EDICIÓN DE PACIANO DEL CARDENAL SÁENZ DE AGUIRRE
}

The marginal note Maria ex stirpe Danielis found in José Sáenz de Aguirre's edition of Pacian's works comes from a misprint in the editio Coloniensis (or fourth edition) of the Bibliotheca Sanctorum Patrum by Marguerin de La Bigne; the misprint was passed on to the eighth (and last) edition of the aforementioned Bibliotheca (also known as editio Lugdunensis), which is the one followed by Aguirre.

En la edición de las obras de Paciano del Cardenal J. Sáenz de Aguirre ${ }^{1}$ se lee una nota marginal que reza: Maria ex stirpe Danielis y comenta las palabras pater Mariae, Iudaei etiam dominator imperii de Paciano en De Paenitentibus ${ }^{2}$, que se refieren al rey David.

Llamó la atención a V. Noguera que el Cardenal J. Sáenz de Aguirre hiciese una afirmación como la de que la Virgen María perteneciese al linaje del profeta Daniel y escribió este comentario respetuoso de las palabras del ilustre purpurado:

ASCENDIENTE DE MARÍA. No declara San Paciano el sugeto que entiende por el epiteto de ascendiente de Maria, ni da señas bastantes para congeturar de quien habla. El Cardenal de Aguirre indicó ser Daniel, pues en una nota marginal dijo: Maria ex stirpe Danielis; no se con que fundamento, porque los sagrados Evangelistas en ninguna de sus genealogías cuentan a Daniel por ascendente de Jesu Christo. Sospecho que San Paciano entendió a Manasés Rey de Judá, Principe de perversas costumbres en los principios de su Reynado, para cuyo castigo embió Dios los Generales Asirios que le hicieron prisionero, y maniatado le condugeron a Babilonia. Entonces este infeliz Monarca conociendo su situación,

1 Collectio Maxima Conciliorum omnium Hispaniae et Novi Orbis ... Cura et studio Josephi Saenz de Aguirre, Romae, 1694, t. II, p. 97 CIX y 1753, t. I, p. 340 CIX.

2 IX 5. C. Las referencias remiten a L. Rubio Fernández, San Paciano. Obras, Barcelona, 1958. Con L. Rubio coincide casi siempre en los capítulos y párrafos C. Granado, Pacien de Barcelone. Écrits, París, 1995. Granado predica de Nabucodonosor Iudaei etiam dominator imperii contraviniendo a la puntuación del Reginensis Lat. 331. 
se humilló profundamente ante Dios, y penetrado de dolor imploró su misericordia. Oyóle el Señor, tuvo piedad de el, y le restituyó en el trono de sus mayores. Estas circunstancias, y el ser uno de los ascendientes de Jesu Christo, persuaden que pudo hablar de este Monarca San Paciano ${ }^{3}$.

$\mathrm{Ph}$. H. Peyrot anota simplemente: «pater Mariae] scil. Dauid, e cuius genere erat Maria. Pater igitur ualet proauus, voorvader» ${ }^{4}$.

Recientemente C. Granado resume el comentario de V. Noguera en estos términos: «Pater Mariae: Sáenz de Aguirre note en marge: Maria ex stirpe Danielis. Noguera pense à Manasé. Pour Peyrot, l'ancêtre de Marie est David. Comme on sait, le N. T. ne transmet pas la généalogie de Marie» ${ }^{5}$.

La nota marginal Maria ex stirpe Danielis aparece por primera vez en la edición coloniense o cuarta de la Bibliotheca Patrum de M. de La Bigne ${ }^{6}$. Las ediciones de esta Bibliotheca publicadas en París, que son la primera ${ }^{7}$, la segunda ${ }^{8}$, la tercera ${ }^{9}$, la quinta ${ }^{10}$, la sexta ${ }^{11}$ y la séptima ${ }^{12}$ rezan Maria ex stirpe Dauidis. La octava y última o lionesa reza, Ex stirpe Danielis ${ }^{13}$ como la cuarta, que le sirvió de modelo ${ }^{14}$. En la coloniense Danielis se debe a que en la tercera de la Bibliotheca, al igual que en las dos anteriores, la nota marginal Maria ex stirpe Dauidis va seguida en la línea inmediata siguiente, siempre en el margen, de otra, Dan. 4., que da la referencia de la penitencia de Nabucodonosor narrada por el profeta Daniel en el capítulo cuarto y ambas están muy juntas, lo que motivó la confusión de los editores de la coloniense quienes las fusionaron en una sola, omitiendo por errata Davidis. En 1749 Fsco. Combefis, que para su Bibliotheca ${ }^{15}$ tomó el texto de la edición cuarta de la Bibliotheca de M. de La Bigne, advirtió en el margen: «Davidis paeni-

3 D. Paciani Episcopi Barcilonensis Opera quae extant, Valencia, 1780, p. 54 (X).

4 Paciani Barcelonensis Episcopi Opuscula, Zwolle, 1896 / Amsterdam, 1969, p. 118 (d).

5 Op. c., p. 289.

6 Coloniae Agrippinae, 1618, t. IV, p. $245 \mathrm{H}$.

7 a. 1575 , I, col. $528 \mathrm{D}$.

8 a. 1589 , III, col. 455 D.

9 a. 1609 , IV, p. 117 B.

10 a. 1624 , II, col. 73 B.

11 a. 1644 , ib.

12 a. 1654, ib. Estas dos últimas ediciones presentan exactamente el mismo texto. En el artículo citado en la nota 6 corríjase en p. 314 «tomo tercero» en «tomo segundo».

13 Lugduni, a. 1677 , p. 317 A.

14 Ángel Anglada, «El texto de Paciano en la Bibliotheca Patrum de Marguerin de La Bigne», en Homenaje a Pedro Sáinz Rodríguez, Madrid, 1986, I, p. 314.

15 Bibliotheca Patrum Concionatoria ... Opera et studio Francisci Combefis Ordinis FF. Praedicatorum Congregationis Sancti Ludovici, Venetiis, 1749, VI, p. 487. 
tentia.I Mariae palrens. Emen.I marginea I Colon. Malria ex stirpe | Danielis: Ipro, Davildis. I Nabucholdonosorisl Regis. Dan. 4 v. $30^{16}$ », indicando así que se debía enmendar Danielis en Dauidis. Aguirre para su edición copió el texto de la lugdunense u octava y última de la Bibliotheca de M. de La Bigne añadiendo al margen algunas lecturas del Reginensis y algunas notas marginales de la octava edición de M. de La Bigne. Noguera conocía igualmente la edición octava de la Bibliotheca de M. de La Bigne, pues dice:

En las grandes Colecciones, llamadas Bibliotecas de los Padres, cuya impresión se ha repetido varias veces, siempre se han incluido los escritos de San Paciano, y sus ediciones se han hecho por las de Paris y Roma, sin mas variedad que la que resulta de entrambas. Por ellas publicó la suya nuestro sapientísimo Cardenal Aguirre en el segundo tomo de su gran Colección de los Concilios de España impresa en Roma año de 1694. Añadióla algunas oportunas notas para ilustrar y aclarar el sentido de algunas expresiones; y en la que precede a dicha obra previno haver cotejado su edición con el manuscrito que poseyó la Reyna Cristina de Suecia y se conserva en la Biblioteca Vaticana, cuyas variantes notó al margen ${ }^{17}$.

Noguera está en lo cierto cuando dice que las Bibliotecas se hicieron por la edición de París, es decir, por la editio princeps de Jean du Tillet, el más joven ${ }^{18}$. En la de Roma publicada en 1564 por Paulo Manucio, hijo de Aldo, puso sus anotaciones marginales Latino Latini ${ }^{19}$, recogidas por Domenico Magri en su Bibliotheca Sacra et Profana ${ }^{20}$. De la edición de 1564 tomó el texto del De Baptismo E. Flórez ${ }^{21}$. Ninguna otra edición consultó el texto de la romana de 1564, por lo que resulta inexacta la indicación de que las Bibliotecas se hicieron también por esta edición.

16 Ángel Anglada, «Paciano en la Bibliotheca Patrum Concionatoria de Francisco Combefis» en Latinitas Biblica et Christiana. Studia philologica varia in honorem Olegario García de La Fuente, Madrid, 1994, p. 235.

17 Op. c., p. LXVIII.

18 Sobre esta edición véase Ángel Anglada, «La editio princeps, de las obras de Paciano de Barcelona» en Miscel-lània Sanchis Guarner (Quaderns de Filologia), Valencia 1984, II pp. 17-22. En p. 235, 1. 29 se lee «margine», corríjase en «marginea».

19 Ángel Anglada, «Las apostillas de Latino Latini al texto de Paciano de Barcelona», Vetera Christianorum 23, 1986, pp. 247, 252, 256, 259, 262, 263, 266.

20 Latini Latinii Viterbiensis Bibliotheca Sacra et Profana sive observationes, correctiones, coniecturae \& variae lectiones in sacros, et profanos scriptores e marginalibus notis codicum eiusdem -, Romae, MDCLXXVII. Las apostillas al texto de Paciano se leen en la p. 157.

21 Ángel Anglada, «La fuente de la edición del De Baptismo de Paciano en España Sagrada de E. Flórez», Analecta Malacitana 20, 1997, pp. 433-445. 
Conclusión.

La nota marginal de Aguirre Maria ex stirpe Danielis tiene su origen en una errata de imprenta de la edición cuarta o coloniense de la Bibliotheca Patrum de Marguerin de La Bigne de 1618. De ésta pasa únicamente a la edición lionesa u octava y última de esta Bibliotheca. Fr. Combefis en 1749 indica a los predicadores que debe corregirse la errata. En 1694 José Sáenz de Aguirre la copia literalmente de la edición lionesa y en 1753 la repite J. Catalani cuando reedita la Collectio de Aguirre.

ÁNGEl ANGLADA 